\title{
An adult B-cell precursor acute lymphoblastic leukemia with multiple secondary cytogenetic aberrations
}

\author{
Walid AL-Achkar ${ }^{1 *}$, Abdulsamad Wafa ${ }^{1}$, Moneeb Abdullah Kassem Othman ${ }^{3}$, Faten Moassass ${ }^{1}$, \\ Abdulmunim Aljapawe ${ }^{2}$ and Thomas Liehr ${ }^{3}$
}

\begin{abstract}
Background: We report a clinically diagnosed acute lymphoblastic leukemia (ALL) with yet unreported secondary chromosomal aberrations.

Results: A complete cytogenetic and molecular cytogenetic analysis, using GTG banding, fluorescence in situ hybridization (FISH) and array-proven multicolor banding (aMCB), for a female patient with clinically diagnosed ALL and immunophenotypically confirmed pre-B ALL (FAB classifications), revealed the presence of a complex structural rearrangement, der (2) (20qter- > 20q13.33::2q21- > 2p14::2q21 > 2qter) along with t (9;22) (q34;q11), t (12;14) (q12;p12) and a monosomy of chromosome 7.
\end{abstract}

Conclusions: Molecular cytogenetic studies are suited best for identification and characterization of chromosomal rearrangements in acute leukemia. Single case reports as well as large scale studies are necessary to provide further insights in karyotypic changes taking place in human malignancies.

Keywords: Acute lymphoblastic leukemia, Secondary chromosomal abnormalities, Philadelphia chromosome, Fluorescence in situ hybridization, Array-proven multicolor banding, Prognostic factors

\section{Background}

Acute lymphoblastic leukemia (ALL) is a heterogeneous disease characterized by multiple subtypes [1]. To date, several structural and numerical chromosomal abnormalities have been characterized in ALL and according to the WHO classification the following, seven genetic subtypes are defined for $\mathrm{B}$ lymphoblastic leukemia, $\mathrm{t}$ (9:22) (q34;q11.2), 11q23 traslocations, t (12;21) (p13;q22), t $(1 ; 19)$ (q23;p13.3), t (5;14) (q31; 32$)$, hyperdiploidy and hypodiploidy [2]. Among the genetic subtypes, Philadelphia $(\mathrm{Ph})$ chromosome, which results from a reciprocal translocation between Abelson $(A B L 1)$ from chromosome 9 and breakpoint cluster region $(B C R)$ from chromosome 22 , is the most frequent cytogenetic aberration which is found in 25\% of adult ALL cases, and in more than $50 \%$ of patients, aged 50 years or more [3,4]. The presence of

\footnotetext{
* Correspondence: ascientific@aec.org.sy

'Department of Molecular Biology and Biotechnology, Human Genetics Division, Atomic Energy Commission of Syria, P.O. Box 6091, Damascus, Syria Full list of author information is available at the end of the article
}

the BCR-ABL1 rearrangement worsens the prognosis of ALL and represents the most significant adverse prognostic marker that influences the disease outcome [5]. Ph positive $(\mathrm{Ph}+)$ ALL is a more aggressive disease than chronic myeloid leukemia (CML), indicating that other factors than BCR-ABL1 are involved in its development and progression $[5,6]$. $\mathrm{Ph}+$ precursor-B-ALL is highly aggressive, frequently resistant to chemotherapy and with a short survival time [6,7]. Here, we are presenting a $\mathrm{Ph}+$ pre-B-ALL case with yet unreported translocation events involving six different chromosomes and a monosomy 7. These chromosomal rearrangements appeared after unsuccessful chemotherapy treatment.

\section{Case presentation}

A 31-year-old woman was diagnosed as suffering from ALL in September 2011. Anemia, thrombocytopenia, diarrhea, fatigue and weight loss were the indicative symptoms. She was treated as follows: after the first GM-ALL protocol (phase I and II) failed, Flag-IDA protocol was 
used, which also did not succeed. Then again GM-ALL protocol (phase I and II) was applied and after being unsuccessful hyper-CVAD was applied. At this point the first cytogenetics and hematology were determined. The patient's hematologic parameters were white blood cells (WBC) at $123 \times 10^{9} / \mathrm{l}$, consisting of $12 \%$ neutrophils, $75 \%$ lymphocytes, $11 \%$ monocytes and $1 \%$ basophiles. Red blood cell (RBC) count was $3.26 \times 10^{6} / \mathrm{mm}^{3}$, hemoglobin level $9.7 \mathrm{~g} / \mathrm{dl}$ and the platelet count $34 \times 10^{9} / \mathrm{l}$. Serum lactate dehydrogenase (LDH) value was 2,712 U/l (normal value up to $480 \mathrm{U} / \mathrm{l}$ ), serum alkaline phosphates value 208 $\mathrm{U} / \mathrm{l}$ (normal value up to $128 \mathrm{U} / \mathrm{l}$ ), serum alanine aminotransferase $198 \mathrm{U} / \mathrm{l}$ (normal value up to $40 \mathrm{U} / \mathrm{l}$ ) and serum aspartate aminotransferase value $139 \mathrm{U} / \mathrm{l}$ (normal value up to $40 \mathrm{U} / \mathrm{l}$ ). The patient was treated further according to standard ALL chemotherapy protocols for fourteen months, however, without clinical success of chemotherapy. Unfortunately she died under the treatment.

\section{Results}

A sample of a female patient diagnosed as pre B-ALL, according to FAB classifications, was received after the completion of three different protocols of chemotherapy. The conventional cytogenetics analysis by GTG banding revealed the karyotype as $45, \mathrm{XX},-7$, der $(2) \mathrm{t}(2 ; 20)$ (?;?), t (9;22) (q34;q11), t (12;14) (q?;p?) [12] / 46, XX, t $(12 ; 14)$ (q?;p?) [10] (Figure 1). The dual color FISH using the probe specific for BCR and ABL and WCP probes specific for chromosomes 2, 7, 12, 14 and 20 confirmed the presence of BCR/ABL fusion on der (22) (data not shown), and the presence of the other rearrangements. To further characterize the breakpoints, aMCB was performed, as previously reported [8] (Figure 2) and the final karyotype was redefined as: $45, \mathrm{XX},-7$, der (2) (20qter- > 20q13.33::2q21->2p14::2q21 > 2qter), t $(9 ; 22)$ (q34;q11), t (12;14) (q12;p12) [12] / 46, XX, t (12;14) (q12;p12) [10].

The abnormal cell population showed the following immunophenotype, which was consistent with pre-BALL (FAB classifications): CD45+, HLADr+, CD117+, CD34+, CD19+, CD10+, CD38+ and expressed CD123 and CD11c (52\%) heterogeneously. The abnormal cells negatively reacted with antibodies to CD5, CD64 and CD3.

\section{Conclusions}

We characterized a $\mathrm{Ph}+$ adult pre-B-ALL case with a complex secondary chromosomal abnormality, a translocation and a monosomy 7. According to the literature, not a single case of ALL showed a der (2) (20qter- $>$ 20q13.33::2q21-> 2p14::2q21-> 2qter) plus a t $(12 ; 14)$ (q12;p12) [9]. Moreover, a t (12;14) (q12;p12) was observed only in two cases of mantle cell lymphoma [9] and in a case of acute myeloid leukemia [10]. On the other hand, the chromosomal bands, 2p14, 2q21, 12q12, and $14 \mathrm{p} 12$ are listed in 5, 32, 20, and 4 cases, respectively, in other rearrangements involving different chromosomes than the ones which are involved in the present case, in previously reported ALL cases [9]. In addition, inv (2) with $2 \mathrm{q} 21$ as one of the breakpoints has also been reported in 3 cases of ALL [9].

Till date, several chromosomal aberrations such as $\mathrm{t}$ $(9 ; 22), \mathrm{t}(4 ; 11), \mathrm{t}(1 ; 9)$, and hyperdiploid or hypodiploid karyotype have been associated with the prognostic

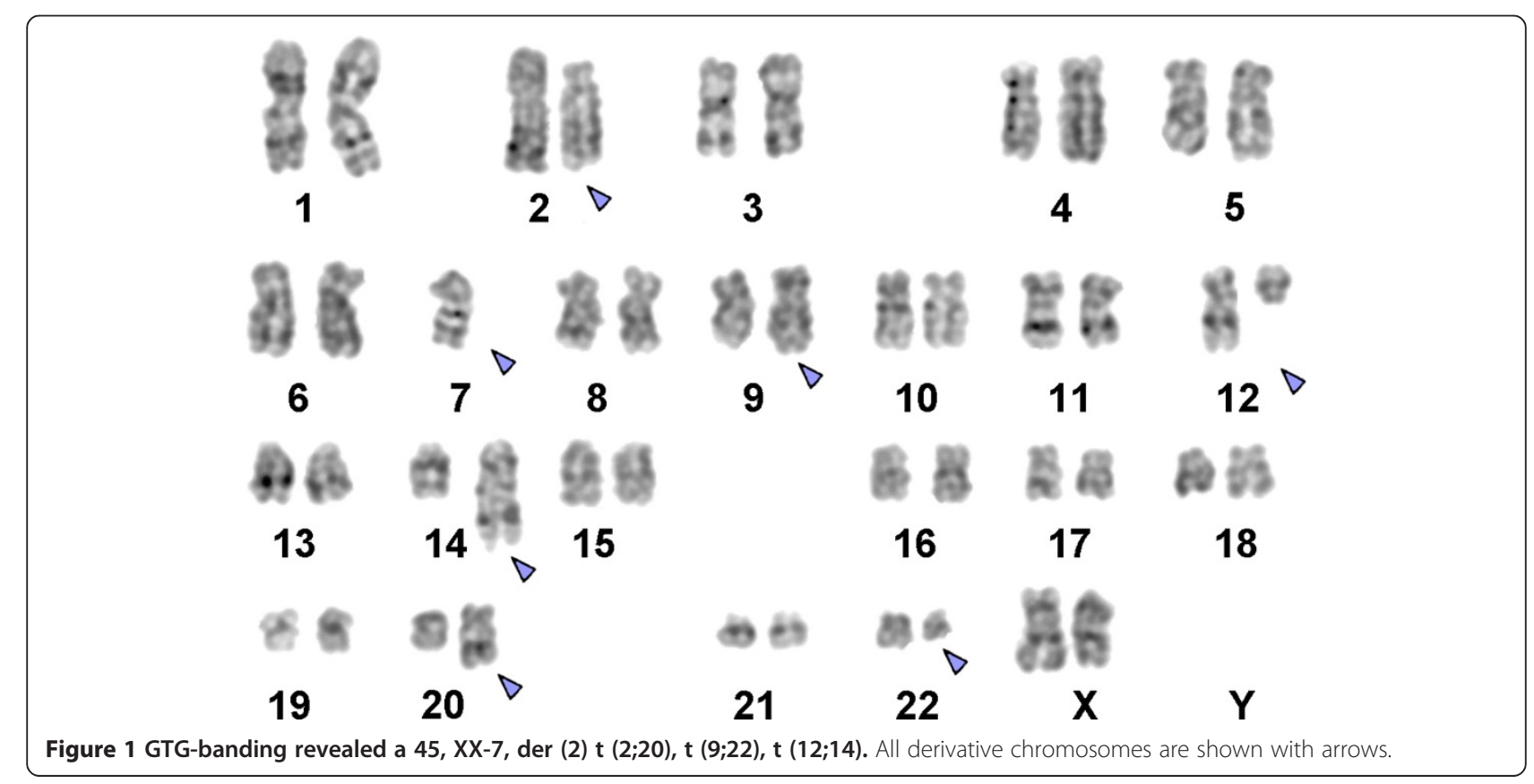




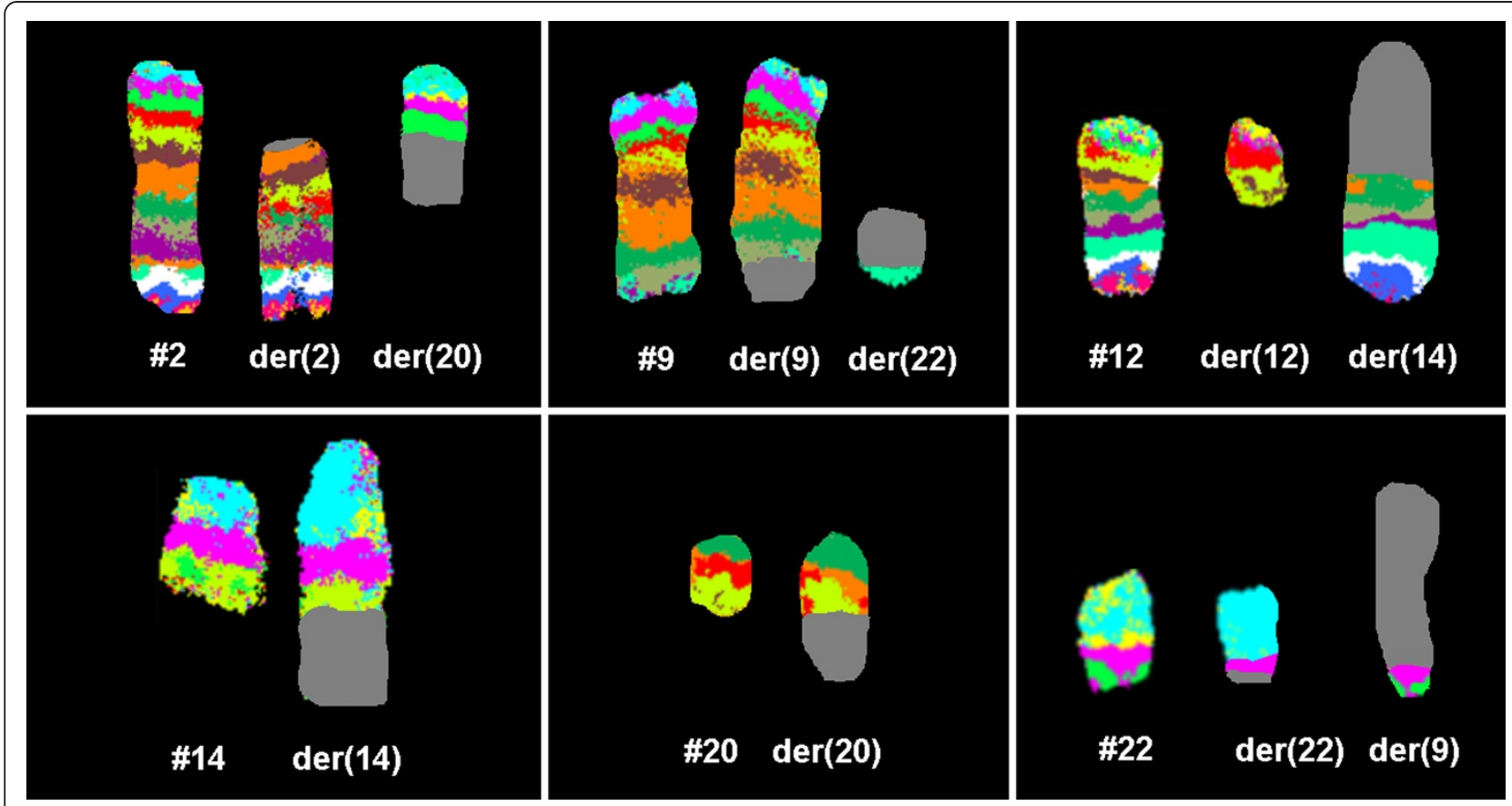

Figure 2 Array-proven multicolor banding (aMCB) was applied to characterize the breakpoint locations. Each image shows the results of MCB analysis using probe sets for chromosomes 2, 9, 12, 14, 20 and 22. The normal chromosomes are shown in the left side of each image and the derivative chromosomes on the right. The $\mathrm{MCB}$-probes unstained regions on the derivative chromosomes are shown in gray. Abbreviations: \# = chromosome; der = derivative chromosome; $\mathrm{Ph}=$ Philadelphia chromosome.

outcome in ALL cases. Apart from t (9;22) (q34;q11)/ BCR-ABL and $t(4 ; 11)$ (q21;q23)/MLL-AF4, an elevated white blood cell count, age over 40 and non-responders/ slow responders to chemotherapy are commonly regarded as high risk criteria in ALL [11]. Monosomy 7, as a sole secondary abnormality, is also related with a poor prognosis and shorter survival in adult ALL cases $[12,13]$. In addition, deletions of $7 p$ confer with an inferior outcome in children with ALL, regardless of the presence of other poor prognostic features, whereas deletions of $7 q$ are not associated with an adverse outcome [14]. The tendency for an adverse prognosis in patients with secondary loss of chromosome 7 or $7 p$ in $\mathrm{Ph}+\mathrm{ALL}$ may be the cumulative result of these events. Mullighan et al. [15] recently described a deletion of IKZF1 gene which encodes the transcription factor Ikaros, located on $7 \mathrm{p} 12$ in $83.7 \%$ of $\mathrm{Ph}+$ ALL cases but not in chronicphase CML, suggesting that loss of Ikaros, a prototypical member of the Krüppel-like zinc finger ( $\mathrm{ZnF}$ ) transcription factor subfamily, which is required for normal hematopoietic differentiation and proliferation, particularly in lymphoid lineages, [16-18] is an important step in the progression of Ph + ALL. Recently, two of seven myeloproliferative neoplasms patients with loss of IKZF1 due to monosomy 7 have also been reported which suggests that IKZF1 may represent an important tumorsuppressor gene affected by monosomy 7 [19].
The presence of the underlying $\mathrm{BCR} / \mathrm{ABL}$ gene rearrangement in CD10 B-cell precursor ALL has been reported previously [20] and it has already been demonstrated that the occurrence of BCR-ABL positive ALL in comparison to $\mathrm{BCR}-\mathrm{ABL}$ negative disease represents a subgroup with a worse prognosis within the CD10+ Blineage ALL [21].

In conclusion, the present case is a de novo case of adult pre-B-ALL with yet unreported translocation events involving six different chromosomes in addition to monosomy 7.

\section{Materials and methods}

\section{Chromosome analysis}

Chromosome analysis using GTG-banding was performed according to standard procedures [22] 12 months after ignition of the chemotherapeutic treatment. A minimum of 20 metaphase cells derived from unstimulated bone marrow culture were analyzed. Karyotypes were described according to the International System for $\mathrm{Hu}$ man Cytogenetic Nomenclature [23].

\section{Molecular cytogenetics}

Fluorescence in situ hybridization (FISH) using LSI $\mathrm{BCR} / \mathrm{ABL}$ three-color dual-fusion translocation probe (Abbott Molecular/Vysis, Des Plaines, IL, USA) was applied according to manufacturer's instructions together 
with a whole chromosome painting (WCP) probe for chromosomes 2, 7, 12, 14 and 20 (MetaSystems, Altlussheim, Germany) [22]. FISH using the corresponding chromosome specific array-proven multicolor banding (aMCB) probe sets based on microdissection derived region-specific libraries was performed as previously reported [8]. A minimum of 20 metaphase spreads were analyzed, using a fluorescence microscope (AxioImager.Z1 mot, Carl Zeiss Ltd., Hertfordshir, UK) equipped with appropriate filter sets to discriminate between a maximum of five fluorochromes plus the counterstain DAPI (4',6- diamino-2-phenylindole). Image capture and processing were performed using an ISIS imaging system (MetaSystems).

\section{Flow cytometric immunophenotype}

Flow cytometric analysis was performed using a general panel of fluorescent antibodies against the following antigens typical for different cell lineages and cell types: CD1a, CD2, CD3, CD4, CD5, CD8, CD10, CD11b, CD11c, CD13, CD14, CD15, CD16, CD19, CD20, CD22, CD23, CD32, CD33, CD34, CD38, CD41a, CD45, CD56, CD57, CD64, CD103, CD117, CD123, CD138, CD209, CD235a and CD243; In addition to antibodies to Kappa and Lambda light Chains, IgD, sIgM, and HLADr. All antibodies were purchased from BD Biosciences. Samples were analyzed on a BD FACSCalibur ${ }^{\text {Tw }}$ flow cytometer. Autofluorescence, viability, and isotype controls were included. Flow cytometric data acquisition and analysis were conducted by BD Cellquest ${ }^{\mathrm{mw}}$ Pro software.

\section{Consent}

Written informed consent was obtained from the patient for publication of this Case Report. A copy of the written consent is available for review by the Editor-in-Chief of this journal.

\section{Competing interests}

The authors declare that they have no competing interests.

\section{Authors' contributions}

AW and FM provided the case and/or did primary cytogenetic and main part of the FISH-tests; AA did the flow cytometry analysis; TL and MAKO did detailed FISH studies. WA supervised the cytogenetic analysis as Director of the MBBD HGD. WA and TL drafted the paper and all authors read and approved the final manuscript.

\section{Acknowledgements}

We thank Prof. I. Othman, the Director General of Atomic Energy Commission of SYRIA (AECS) and Dr. N. Mirali, Head of Molecular Biology and Biotechnology Department for their support. This work was supported by the AECS, in parts by the DAAD, Stefan-Morsch-Stiftung and the Monika-Kutzner-Stiftung.

\section{Author details}

${ }^{1}$ Department of Molecular Biology and Biotechnology, Human Genetics Division, Atomic Energy Commission of Syria, P.O. Box 6091, Damascus, Syria. ${ }^{2}$ Department of Molecular Biology and Biotechnology, Mammalians Biology Division, Atomic Energy Commission, Damascus, Syria. ${ }^{3}$ Institute of Human Genetics, Jena University Hospital, Jena, Germany.
Received: 9 June 2014 Accepted: 21 August 2014

Published online: 10 September 2014

\section{References}

1. Faderl S, Jeha S, Kantarjian HM: The biology and therapy of adult acute lymphoblastic leukemia. Cancer 2003, 98:1337-1354.

2. WHO Classification of Tumours of Haematopoietic and Lymphoid Tissues. Lyon: IARC; 2008

3. Secker-Walker LM, Craig JM, Hawkins JM, Hoffbrand AV: Philadelphia positive acute lymphoblastic leukemia in adults: age distribution, $B C R$ breakpoint and prognostic significance. Leukemia 1991, 5:196-199.

4. Bernt KM, Hunger SP: Current concepts in pediatric Philadelphia chromosome-positive acute lymphoblastic leukemia. Front Oncol 2014, 4:54.

5. Faderl S, Kantariian HM, Thomas DA, Cortes J, Giles F, Pierce S, Albitar M, Estrov Z: Outcome of Philadelphia chromosome-positive adult acute lymphoblastic leukemia. Leuk Lymphoma 2000, 36:263-273.

6. Radich JP: Philadelphia chromosome-positive acute lymphocytic leukemia. Hematol Oncol Clin North Am 2001, 15:21-36.

7. Secker-Walker LM, Pentrice HG, Durrant J, Richards S, Hall E, Harrison G Cytogenetics adds independent prognostic information in adults with acute lymphoblastic leukaemia on MRC trial UKALL XA. Br J Haematol 1997, 96:601-610.

8. Liehr T, Heller A, Starke H, Rubtsov N, Trifonov V, Mrasek K, Weise A, Kuechler A, Claussen U: Microdissection based high resolution multicolor banding for all 24 human chromosomes. Int J Mol Med 2002, 9:335-339.

9. Mitelman F, Johansson B, Mertens F: Mitelman database of chromosome aberrations and gene fusions in cancer (2012). Available at: http://cgap. nci.nih.gov/Chromosomes/Mitelman [last accessed 04.06.2014].

10. Lugthart S, Gröschel S, Beverloo HB, Kayser S, Valk PJ, van Zelderen-Bhola SL, Jan Ossenkoppele G, Vellenga E, van den Berg-de Ruiter E, Schanz U, Verhoef $\mathrm{G}$, Vandenberghe P, Ferrant A, Köhne $\mathrm{CH}$, Pfreundschuh M, Horst HA, Koller E, von Lilienfeld-Toal M, Bentz M, Ganser A, Schlegelberger B, Jotterand M, Krauter J, Pabst T, Theobald M, Schlenk RF, Delwel R, Döhner K, Löwenberg B, Döhner H: Clinical, molecular, and prognostic significance of WHO type inv (3) (q21q26.2)/t (3;3) (q21;q26.2) and various other $3 q$ abnormalities in acute myeloid leukemia. J Clin Oncol 2010, 28:3890-3898.

11. Hoelzer D, Gokbuget N: New approaches to acute lymphoblastic leukemia in adults: where do we go? Semin Oncol 2000, 27:540-559.

12. Wetzler M, Dodge RK, Mrozek K, Stewart CC, Carroll AJ, Tantravahi R, Vardiman JW, Larson RA, Bloomfield CD: Additional cytogenetic abnormalities in adults with Philadelphia chromosome positive acute lymphoblastic leukaemia: a study of the Cancer and Leukaemia Group B. Br J Haematol 2004, 124:275-288.

13. Wetzler M, Dodge RK, Mrózek K, Carroll AJ, Tantravahi R, Block AW, Pettenati MJ, Le Beau MM, Frankel SR, Stewart CC, Szatrowski TP, Schiffer CA, Larson RA, Bloomfield CD: Prospective karyotype analysis in adult acute lymphoblastic leukemia: the cancer and leukemia Group B experience. Blood 1999, 93:3983-3993.

14. Heerema NA, Nachman JB, Sather HN, La MK, Hutchinson R, Lange BJ, Bostrom B, Steinherz PG, Gaynon PS, Uckun FM, Children's Cancer Group: Deletion of $7 p$ or monosomy 7 in pediatric acute lymphoblastic leukemia is an adverse prognostic factor: a report from the Children's Cancer Group. Leukemia 2004, 18:939-947.

15. Mullighan CG, Miller CB, Radtke I, Phillips LA, Dalton J, Ma J, White D, Hughes TP, Le Beau MM, Pui CH, Relling MV, Shurtleff SA, Downing JR: BCR-ABL1 lymphoblastic leukaemia is characterized by the deletion of Ikaros. Nature 2008, 453:110-114.

16. Georgopoulos K, Bigby M, Wang JH, Molnar A, Wu P, Winandy S, Sharpe A: The lkaros gene is required for the development of all lymphoid lineages. Cell 1994, 79:143-156.

17. Kirstetter $P$, Thomas $M$, Dierich A, Kastner $P$, Chan S: Ikaros is critical for $B$ cell differentiation and function. Eur I Immunol 2002, 32:720-730.

18. Westman BJ, Mackay JP, Gell D: Ikaros: a key regulator of haematopoiesis. Int J Biochem Cell Biol 2002, 34:1304-1307.

19. Jäger $R$, Gisslinger $H$, Passamonti $F$, Rumi E, Berg T, Gisslinger $B$, Pietra $D$, Harutyunyan A, Klampfl T, Olcaydu D, Cazzola M, Kralovics R: Deletions of the transcription factor Ikaros in myeloproliferative neoplasms. Leukemia 2010, 24:1290-1298.

20. Primo D, Tabernero MD, Perez JJ, Rasillo A, Sayagues JM, Espinosa AB, Lopez-Berges MC, Garcia-Sanz R, Gutierrez NC, Hernandez JM, Romero M, 
Osuna CS, Giralt M, Barbon M, San Miguel JF, Orfao A: Genetic heterogeneity of BCR/ABL adult B-cell precursor acute lymphoblastic leukemia: impact on the clinical, biological and immunophenotypical disease characteristics. Leukemia 2005, 19:713-720.

21. Gleissner B, Gökbuget N, Bartram CR, Janssen B, Rieder H, Janssen JW, Fonatsch C, Heyll A, Voliotis D, Beck J, Lipp T, Munzert G, Maurer J, Hoelzer D, Thiel E, German Multicenter Trials of Adult Acute Lymphoblastic Leukemia Study Group: Leading prognostic relevance of the BCR-ABL translocation in adult acute B-lineage lymphoblastic leukemia: a prospective study of the German Multicenter Trial Group and confirmed polymerase chain reaction analysis. Blood 2002, 99:1536-1543.

22. AL-Achkar W, Wafa A, Nweder MS: A complex translocation t $(5 ; 9 ; 22)$ in Philadelphia cells involving the short arm of chromosome 5 in a case of chronic myelogenous leukemia. J Exp Clin Cancer Res 2007, 26:411-415.

23. Shaffer LG, Slovak ML, Cambell L, ISCN: International System for Human Cytogenetic Nomenclature. Basel: S Karger AG; 2009.

doi:10.1186/s13039-014-0060-0

Cite this article as: AL-Achkar et al:: An adult B-cell precursor acute

lymphoblastic leukemia with multiple secondary cytogenetic aberrations. Molecular Cytogenetics 2014 7:60.

\section{Submit your next manuscript to BioMed Central and take full advantage of:}

- Convenient online submission

- Thorough peer review

- No space constraints or color figure charges

- Immediate publication on acceptance

- Inclusion in PubMed, CAS, Scopus and Google Scholar

- Research which is freely available for redistribution 